\title{
Modeling the Relationship between Parents Valuing the Importance of Children's Education Relative to Parents' Entertainment and Parents' Well-Being and Investment Behavior in Education
}

\author{
Tin-Chun Lin \\ School of Business and Economics, Indiana University-Northwest, Gary, IN, USA \\ Email: tinlin@iu.edu
}

How to cite this paper: Lin, T.-C. (2021). Modeling the Relationship between Parents Valuing the Importance of Children's Education Relative to Parents' Entertainment and Parents' Well-Being and Investment Behavior in Education. Theoretical Economics Letters, 11, 1090-1100.

https://doi.org/10.4236/tel.2021.116069

Received: October 16, 2021

Accepted: November 13, 2021

Published: November 16, 2021

Copyright $\odot 2021$ by author(s) and Scientific Research Publishing Inc. This work is licensed under the Creative Commons Attribution International License (CC BY 4.0).

http://creativecommons.org/licenses/by/4.0/

\begin{abstract}
We used the theory of consumer choice to build a model that links the relationship between how much parents value the importance of children's education relative to parents' entertainment and parents' utility (well-being) and investment behavior in education. Our theoretical analysis suggests that parents valuing the importance of children's education relative to parents' entertainment are positively associated with parents' demand for their children's education, but the effect is uncertain on parental utility. With graphical proof, we found a certain and clear positive effect-parents' utility indeed increases when parents increase their valuation on the importance of children's education relative to parents' entertainment. The main contribution of this study is in framing an economic theoretical model that can be useful in constructing empirical models for further investigation of this issue.
\end{abstract}

\section{Keywords}

Children's Education, Parental Well-Being, Parental Investment Behavior in Education, Economic Theoretical Model

\section{Introduction}

When you find yourself with extra cash, how do you spend it to improve your utility (well-being)? Are your choices and utility influenced by the presence of school-age (K-12) children in your home? In other words, you may face a crucial 
choice-do you want to spend your extra funds on something that you will enjoy or invest it to upgrade your school-age children's human capital?

If you value children's education beyond all things, then it is more likely that you may spend most (or all) of your extra funds on your children's education, such as sending children to after-school enrichment programs (e.g., Kumon Math \& Reading Program, HGS Music, Illinois Shotokan Karate Clubs, etc.) to extend their learning and enhance their skills, knowledge, and well-being. On the other hand, you may value your quality of life, making it more likely that you may spend most (or all) of your extra funds on personal entertainment (e.g., travel, shopping festivals, road trips, etc.) to enrich your utility (well-being). Alternatively, you may equally value both children's education and personal entertainment; if so, you may optimally allocate funds both toward your children's education and your entertainment to improve your well-being.

Therefore, the apportionment of your spare funds toward one choice, or the other, or both may depend on how much you value the importance of your children's education relative to your entertainments. If you believe that education is a crucial way to upgrade your children's social status (Lin \& Lv, 2017), helping them to attain a higher social class in the future, then you may value children's education beyond your entertainment, vice versa. In other words, as proven by Hao and Yeung (2015), parental expectations and beliefs may play a critical role in determining how parents spend money on their school-age children. In addition, empirical evidence (e.g., Omori, 2010) has demonstrated that parental income and education level are other essential factors that can influence how parents spend money on children's education, entertainments, etc. Furthermore, another empirical study done by Dan (2020) has shown that a mother's labor participation level would affect family education expenditures and in turn influence children's academic performance. Moreover, race can be another determinant of how parents allocate their expenditures toward children's education (e.g., Fan \& Lewis, 1999). As demonstrated by Fan and Lewis (1999), given the same income group, different racial groups allocate their budget differently. For example, among higher-income households, Asian Americans spend the most on education than do other racial groups, such as White American, African American, and Hispanic American households. Yet, among lower-income households, White Americans spend the most on education than do the other racial groups (i.e., Asian American, African American, and Hispanic American households).

Numerous studies have shown the many ways that education contributes to a nation's economic growth and reduces a nation's income inequality (e.g., Armer \& Liu, 1993; Tallman \& Wang, 1994; Lin, 2003a, 2003b, 2004; Mercan \& Sezer, 2014; Grant, 2017) as well as how expenditures on children's education influence children's economic well-being (e.g., Meyer \& Sullivan, 2008). This study takes a different track, aiming instead at parents' investment behavior in education and their utility (well-being). Accordingly, we adopt the theory of consumer choice 
to model the relationship between how much parents value the importance of children's education relative to parents' entertainment and their investment behavior in their children's education. In addition, we investigate the effect of parents valuing the importance of children's education relative to parents' entertainment on parents' utility (well-being). Importantly, this study offers an economic theoretical model that can be useful in constructing empirical models for further investigation of this issue.

This paper is organized as follows. First, an economic theoretical model is developed and equilibriums of children's education and parents' entertainments are determined. Second, a comparative static analysis is used to analyze the relationship between parents valuing the importance of children's education relative to parents' entertainment and their investment behavior in their children's education. Third, we explore ways to identify the effect of parents valuing the importance of children's education relative to parents' entertainment on parents' utility (well-being). Finally, conclusions can be found in the final section.

\section{The Model}

\subsection{The Utility Function}

In this section, we use the theory of consumer choice to develop a model to link the relationship between parents valuing the importance of children's education relative to parents' entertainment and their investment behavior in their children's education.

It should be noted that to simplify the model, we will use one representative parent to represent married parents, single-parent, or cohabiting household as parent(s) in a one-unit family. Consider that a representative parent who has school-age children in K-12 always spends his/her extra money on two goods yearly: children's education (e.g., after-school enrichment programs, such as Kumon Math \& Reading Program, DreamBox Learning Program, etc.; denoted by $H$, which also indicates the quantity of children's education) and parents' entertainments (e.g., movies, travel, shopping festivals, etc.; denoted by $C$, which also indicates the quantity of entertainments).

Suppose that the representative parent is a rational economic individual who follows "the law of demand", and that these two goods (children's education and parents' entertainments) are normal goods. We also assume that every parent maximizes their utility. Therefore, the parent can be satisfied by investing in their children's education and consuming his/her entertainments. For that reason, the parent's utility function consists of children's education $(H)$, parents' entertainments $(C)$, and the external factors that may affect the parent's utility (denoted by $\Phi)$, such as the state of the economy. The quantities of children's education $(H)$ and parents' entertainments $(C)$ are factors that can be determined by the parent; thus, these two factors are variables. Nevertheless, the external factors $(\Phi)$ that may influence the parent's utility cannot be determined by the parent, so these external factors are constant terms. In addition, we as- 
sume that the parent's utility function exhibits the Cobb-Douglas form, which can be shown as:

$$
U(\Phi ; H, C)=\Phi H^{\alpha} C^{\beta},
$$

where $\alpha$ and $\beta \quad(0<\alpha, \beta<1)$ are constant parameters and shares of children's education $(H)$ and parents' entertainments $(C) ; U_{H}, U_{C}>0 ; U_{H H}, U_{C C}<0$; and $U_{H C}=U_{C H}>0$.

\subsection{The Budget Constraint Line}

Suppose that the opportunity cost of holding money to invest in children's education per unit is $P_{H}$, which is a function of the price of children's education (denoted by $p_{h}$ ) and parents valuing the importance of children's education relative to parents' entertainment (denoted by $\delta_{H C}$, i.e., how much parents value the importance of children's education relative to parents' entertainment). Note: suppose that we can quantify (such as rating) how much parents value the importance of children's education and parents' entertainment (e.g., $1=$ least important and $10=$ most important). For example, let's say that a parent values the importance of children's education as 5 and the importance of his/her entertainment as 4 . Thus, the $\delta_{H C}$ will be equal to $1.25(=5 / 4)$. If the parent increases his/her valuation on the importance of children's education from 5 to 6 but decreases his/her valuation on the importance of his/her entertainment from 4 to 3 , then the $\delta_{\mathrm{HC}}$ will increase from 1.25 to $2(=6 / 3)$.

When the price of children's education becomes more expensive, parents will need to hold more money to buy the same "quantity" of children's education as occurred previously; hence, the opportunity cost of holding money to invest in children's education per unit becomes more expensive (i.e., $\frac{\mathrm{d} P_{H}}{\mathrm{~d} p_{h}}>0$ ). However, when parents increase their valuation on the importance of children's education relative to parents' entertainment, parents would feel that money spent on children's education relative to parents' entertainments would have greater value due to a relatively higher return; thus, the opportunity cost of holding money to invest in children's education per unit would become cheaper (i.e., $\frac{\mathrm{d} P_{H}}{\mathrm{~d} \delta_{H C}}<0$ ). Therefore, $P_{H}=P_{H}\left(p_{h}, \delta_{H C}\right)$.

Similarly, suppose that the opportunity cost of holding money to expend on entertainments per unit is $P_{C}$, which is a function of the price of entertainments (denoted by $p_{c}$ ) and parents valuing the importance of children's education relative to parents' entertainments (denoted by $\delta_{H C}$ ). When the price of entertainments becomes greater, parents will need to hold more money in order to buy the same quantity of entertainments that they consumed in the past; hence, the opportunity cost of holding money to put toward entertainments per unit becomes more expensive (i.e., $\frac{\mathrm{d} P_{C}}{\mathrm{~d} p_{c}}>0$ ). On the other hand, when parents raise 
their valuation on the importance of children's education relative to parents' entertainment, parents would feel that the money spent on their entertainments relative to children's education would have less value due to a relatively lower return. Hence, the opportunity cost of holding money to consume entertainments per unit would become more expensive (i.e., $\left.\frac{\mathrm{d} P_{C}}{\mathrm{~d} \delta_{H C}}>0\right)$ ). Therefore, $P_{C}=P_{C}\left(p_{c}, \delta_{H C}\right)$.

Moreover, we assume that the parent's total budget per year for these two goods is $M$, which will be equal to the total opportunity costs of holding money for consuming these two goods ( $H$ and $C$ ) per year. Consequently, the parent's budget constraint line can be displayed as follows:

$$
P_{H}\left(p_{h}, \delta_{H C}\right) H+P_{C}\left(p_{c}, \delta_{H C}\right) C=M .
$$

\subsection{Equilibrium}

To solve the parent's optimization problem, we can maximize Equation (1) subject to Equation (2) and choose $H$ and $C$. As a result, the Lagrangian expression can be shown as follows:

$$
L=\Phi H^{\alpha} C^{\beta}+\lambda\left(M-P_{H} H-P_{C} C\right),
$$

where $\lambda$ stands for the Lagrangian multiplier or a shadow price. Based upon the Lagrangian expression (Equation (3)), we can solve the first-order conditions for the constrained maximum:

$$
\begin{gathered}
\frac{\alpha \Phi H^{\alpha-1} C^{\beta}}{P_{H}}=\frac{\beta \Phi H^{\alpha} C^{\beta-1}}{P_{C}} \\
M=P_{H} H+P_{C} C
\end{gathered}
$$

According to Equations (4) and (5), we can solve the equilibriums of these two goods:

$$
\begin{gathered}
H^{*}=\frac{\alpha}{\alpha+\beta} \frac{M}{P_{H}}=H\left({\left.\stackrel{-}{P_{H}}, \stackrel{+}{M}\right), \text { and }}^{*}=\frac{\beta}{\alpha+\beta} \frac{M}{P_{C}}=C\left(\stackrel{-}{P}_{C}, \stackrel{+}{M}\right) .\right.
\end{gathered}
$$

We then plug $H^{*}$ and $C^{*}$ into the utility function ( $U$ ), Equation (1), which can be solved as:

$$
\begin{aligned}
U^{*} & =\Phi\left(\frac{\alpha}{\alpha+\beta}\right)^{\alpha}\left(\frac{\beta}{\alpha+\beta}\right)^{\beta} M^{(\alpha+\beta)}\left(P_{H}\left(p_{h}, \delta_{H C}\right)\right)^{-\alpha}\left(P_{C}\left(p_{c}, \delta_{H C}\right)\right)^{-\beta} \\
& =U\left(\stackrel{+}{\Phi}, \stackrel{+}{M}, \vec{P}_{H},-P_{C}\right)
\end{aligned}
$$

As displayed above, the parent maximizes his/her utility at the optimal $U^{*}$ level by choosing his/her optimal combination of children's education and parents' entertainments ( $H^{*}$ and $C^{*}$ ). As a result, equilibrium for children's edu- 
cation $\left(H^{*}\right)$ is associated with the opportunity cost of holding money to invest in children's education per unit $\left(P_{H}\right)$ and total budget $(M)$; while equilibrium for parents' entertainments $\left(C^{*}\right)$ is associated with the opportunity cost of holding money to engage in entertainments per unit $\left(P_{H}\right)$ and total budget $(M)$. Moreover, the parent's equilibrium utility $\left(U^{*}\right)$ is associated with the external factors $(\Phi)$, total budget $(M)$, the opportunity cost of holding money to invest in children's education per unit $\left(P_{H}\right)$, and the opportunity cost of holding money to engage in entertainments per unit $\left(P_{H}\right)$.

\section{Comparative Static Analysis}

In this section, we demonstrate the comparative static analysis. We first totally differentiate Equations (4) and (5) and yield:

$$
\left[\begin{array}{cc}
U_{H H} P_{C}-U_{C H} P_{H} & U_{H C} P_{C}-U_{C C} P_{H} \\
P_{H} & P_{C}
\end{array}\right]\left[\begin{array}{l}
\mathrm{d} H \\
\mathrm{~d} C
\end{array}\right]=\left[\begin{array}{ccc}
0 & U_{C} & -U_{H} \\
1 & -H & -C
\end{array}\right]\left[\begin{array}{l}
\mathrm{d} M \\
\mathrm{~d} P_{H} \\
\mathrm{~d} P_{C}
\end{array}\right],
$$

where $U_{H}=\Phi \alpha H^{\alpha-1} C^{\beta}>0$,

$$
\begin{aligned}
& U_{H H}=\Phi \alpha(\alpha-1) H^{\alpha-2} C<0, \\
& U_{H C}=U_{C H}=\Phi \alpha \beta H^{\alpha-1} C^{\beta-1}>0, \\
& U_{C}=\Phi \beta H^{\alpha} C^{\beta-1}>0, \text { and } \\
& U_{C C}=\Phi \beta(\beta-1) H^{\alpha} C^{\beta-2}<0 .
\end{aligned}
$$

Let $|D|$ be the determinant of the pre-multiplied matrix of vector $\left[\begin{array}{ll}\mathrm{d} H & \mathrm{~d} C\end{array}\right]$, which is:

$$
|D|=\left|\begin{array}{cc}
U_{H H} P_{C}-U_{C H} P_{H} & U_{H C} P_{C}-U_{C C} P_{H} \\
P_{H} & P_{C}
\end{array}\right|=\left|\begin{array}{cc}
- & + \\
+ & +
\end{array}\right|<0 .
$$

Second, we use Cramer's rule, so the straight forward comparative analysis yields:

$$
\begin{gathered}
\frac{\mathrm{d} H}{\mathrm{~d} M}=\frac{\left|\begin{array}{cc}
0 & U_{H C} P_{C}-U_{C C} P_{H} \\
1 & P_{C}
\end{array}\right|}{|D|}>0, \\
\frac{\mathrm{d} C}{\mathrm{~d} M}=\frac{\left|\begin{array}{cc}
U_{H H} P_{C}-U_{C H} P_{H} & 0 \\
P_{H} & 1
\end{array}\right|}{|D|}>0, \\
\frac{\mathrm{d} H}{\mathrm{~d} P_{H}}=\frac{\left|\begin{array}{cc}
U_{C} & U_{H C} P_{C}-U_{C C} P_{H} \\
-H & P_{C}
\end{array}\right|}{|D|}<0, \\
\frac{\mathrm{d} C}{\mathrm{~d} P_{H}}=\frac{\left|\begin{array}{cc}
U_{H H} P_{C}-U_{C H} P_{H} & U_{C} \\
P_{H} & -H
\end{array}\right|}{|D|}>\text { or }<0, \\
\frac{\mathrm{d} H}{\mathrm{~d} P_{C}}=\frac{\begin{array}{c}
-C \quad U_{H C} P_{C}-U_{C C} P_{H} \\
-C \quad P_{C}
\end{array} \mid}{|D|}>\text { or }<0, \text { and }
\end{gathered}
$$




$$
\frac{\mathrm{d} C}{\mathrm{~d} P_{C}}=\frac{\left|\begin{array}{cc}
U_{H H} P_{C}-U_{C H} P_{H} & -U_{H} \\
P_{H} & -C
\end{array}\right|}{|D|}<0 .
$$

Intuitively, as demonstrated in Equations (10) and (11), an enhancement in total budget increases demands for both children's education and parents' entertainments. In addition, as shown in Equations (12) and (13), an increase in the opportunity cost of holding money to invest in children's education reduces the parent's demand for children's education but does not provide a certain effect on parents' demand for their entertainments. Similarly, as displayed in Equations (14) and (15), a rise in the opportunity cost of holding money to expand on entertainments decreases the parent's demand for entertainments but does not offer an unambiguous effect on their demand for children's education.

Moreover, according to Equation (12) and $\frac{\mathrm{d} P_{H}}{\mathrm{~d} \delta_{H C}}<0$, we can simply demonstrate the effect of parents valuing the importance of children's education relative to parents' entertainment ( $\left.\delta_{H C}\right)$ on the parent's demand for children's education, which can be presented in the following:

$$
\frac{\mathrm{d} H}{\mathrm{~d} \delta_{H C}}=\frac{\mathrm{d} H}{\mathrm{~d} P_{H}} \frac{\mathrm{d} P_{H}}{\mathrm{~d} \delta_{H C}}=(-) \cdot(-)>0 .
$$

As shown in Equation (16), intuitively, a parent who increases his/her valuation on the importance of children's education relative to entertainment believes that funds spent on that education will result in a higher return, making the opportunity cost a less expensive proposition. Thus, the lower opportunity cost of investing in children's education guarantees that a parent will be more willing to prioritize investment in their children's education.

\section{Further Exploration}

In the previous section, we have provided our comparative static analysis which shows that the effect of parent valuing the importance of children's education relative to their own entertainments $\left(\delta_{H C}\right)$ on parents' demand for children's education is positive. In this section, we investigate the effect of parents valuing the importance of their children's education relative to parents' entertainments $\left(\delta_{H C}\right)$ on parent's utility (i.e., well-being).

Based upon Equation (8), we take the first derivative with respect to $\delta_{H C}$, which can be expressed as below:

$$
\begin{aligned}
\frac{\mathrm{d} U}{\mathrm{~d} \delta_{H C}}= & \Phi\left(\frac{\alpha}{\alpha+\beta}\right)^{\alpha}\left(\frac{\beta}{\alpha+\beta}\right)^{\beta} M^{\alpha+\beta}\left[P_{C}^{-\beta}(-\alpha) P_{H}^{-(\alpha+1)} \frac{\mathrm{d} P_{H}}{\mathrm{~d} \delta_{H C}}\right. \\
& \left.+P_{H}^{-\alpha}(-\beta) P_{C}^{-(\beta+1)} \frac{\mathrm{d} P_{C}}{\mathrm{~d} \delta_{H C}}\right]
\end{aligned}
$$

Due to $\frac{\mathrm{d} P_{H}}{\mathrm{~d} \delta_{H C}}<0$ and $\frac{\mathrm{d} P_{C}}{\mathrm{~d} \delta_{H C}}>0$, Equation (17), $\frac{\mathrm{d} U}{\mathrm{~d} \delta_{H C}}$, can be positive $(>0)$ 
or negative $(<0)$. That is, the effect is uncertain.

To be positive for Equation (17),

$$
\begin{gathered}
P_{C}^{-\beta}(-\alpha) P_{H}^{-(\alpha+1)} \frac{\mathrm{d} P_{H}}{\mathrm{~d} \delta_{H C}}+P_{H}^{-\alpha}(-\beta) P_{C}^{-(\beta+1)} \frac{\mathrm{d} P_{C}}{\mathrm{~d} \delta_{H C}} \text { has to be positive. That is, } \\
\begin{array}{c}
P_{C}^{-\beta}(-\alpha) P_{H}^{-(\alpha+1)} \frac{\mathrm{d} P_{H}}{\mathrm{~d} \delta_{H C}}+P_{H}^{-\alpha}(-\beta) P_{C}^{-(\beta+1)} \frac{\mathrm{d} P_{C}}{\mathrm{~d} \delta_{H C}}>0 \\
\Rightarrow \frac{-\left(\frac{\mathrm{d} P_{H}}{\mathrm{~d} \delta_{H C}}\right)}{\left(\frac{\mathrm{d} P_{C}}{\mathrm{~d} \delta_{H C}}\right)} \frac{P_{C}}{P_{H}}>\frac{\beta}{\alpha} \\
\Rightarrow \frac{-\left(\frac{\mathrm{d} P_{H}}{P_{H}}\right)}{\left(\frac{\mathrm{d} P_{C}}{P_{C}}\right)}>\frac{\beta}{\alpha} .
\end{array}
\end{gathered}
$$

Note that $-\left(\frac{\mathrm{d} P_{H}}{P_{H}}\right)=$ percentage decrease in the opportunity cost of holding money to invest in children's education; while $\left(\frac{\mathrm{d} P_{C}}{P_{C}}\right)=$ percentage increase in the opportunity cost of holding money for consuming entertainments.

The result of (18) implies that if the ratio of the percentage decrease in the opportunity cost of holding money for investing children's education $\left(-\frac{\mathrm{d} P_{H}}{P_{H}}\right)$ and the percentage increase in the opportunity cost of holding money for consuming entertainments $\left(\frac{\mathrm{d} P_{C}}{P_{C}}\right)$ is higher than the ratio of the share of parents' entertainments $(\beta)$ and the share of children's education $(\alpha)$, then the parent's utility (well-being) will improve when the parent valuing the importance of children's education relative to the parent's entertainments $\left(\delta_{H C}\right)$ increases.

For example, let's say that the share of children's education $(\alpha)$ is equal to the share of parents' entertainments ( $\alpha$ ); that is, $\alpha=\beta$, then

$$
\frac{-\left(\frac{\mathrm{d} P_{H}}{P_{H}}\right)}{\left(\frac{\mathrm{d} P_{C}}{P_{C}}\right)}>1 \Rightarrow-\frac{\mathrm{d} P_{H}}{P_{H}}>\frac{\mathrm{d} P_{C}}{P_{C}} .
$$

If the above example is the real case, the result of (19) implies that if the percentage decrease in the opportunity cost of holding money to invest in children's education is greater than the percentage increase in the opportunity cost of holding money for consuming entertainments, the parent's utility (well-being) will increase when the parent raises his/her valuation on the importance of children's education relative to his/her entertainment (i.e., when $\delta_{H C}$ increases). 
Alternatively, we can graphically prove a clear and certain result. As Figure 1 shows, given the parent's initial budget constraint line $m n$, the parent's initial equilibrium is located at $\mathrm{E}^{*}$; thus, the parent's initial optimal combination of children's education and parents' entertainments is ( $\mathrm{HO}, \mathrm{C} 0)$ and the parent's initial utility (well-being) reaches at the U0 level. However, when the parent valuing the importance of children's education relative to the parent's entertainments $\left(\delta_{H C}\right)$ rises, the parent's budget constraint line will rotate from $m n$ to $s t$. As a result, the parent's new equilibrium will be located at $\mathrm{E} 1^{*}$; hence, the parent's new optimal combination of children's education and parents' entertainments will be $(\mathrm{H} 1, \mathrm{C} 1)[\mathrm{H} 1>\mathrm{H} 0$ and $\mathrm{C} 1<\mathrm{C} 0]$ and the parent's new utility (well-being) will reach at a higher level, which is at the U1 level (U1 > U0). Obviously, Figure 1 demonstrates that the parent's utility (well-being) will improve when the parent increases his/her valuation on the importance of children's education relative to the parent's entertainment (i.e., when $\delta_{H C}$ rises).

Furthermore, let's take a closer look at both substitution and income effects. When the parent valuing the importance of children's education relative to parents' entertainments ( $\left.\delta_{\mathrm{HC}}\right)$ rises, the opportunity cost of holding money to invest in children's education decreases, while the opportunity cost of holding money to put toward entertainments increases. Therefore, the relative opportunity cost of holding money for consuming between these two goods (children's education and parents' entertainments) will drop (i.e., $\frac{P_{H}}{P_{C}} \downarrow$ ). As a result, to maintain the same level of utility (well-being), the parent will be more willing to substitute more units of children's education for his/her entertainments. Consequently, the parent will invest more in their children's education (from $\mathrm{H} 0$ to $\mathrm{H} 2$ ) and engage in less entertainments (from $\mathrm{C} 0$ to $\mathrm{C} 2$ ), which is referred to as a

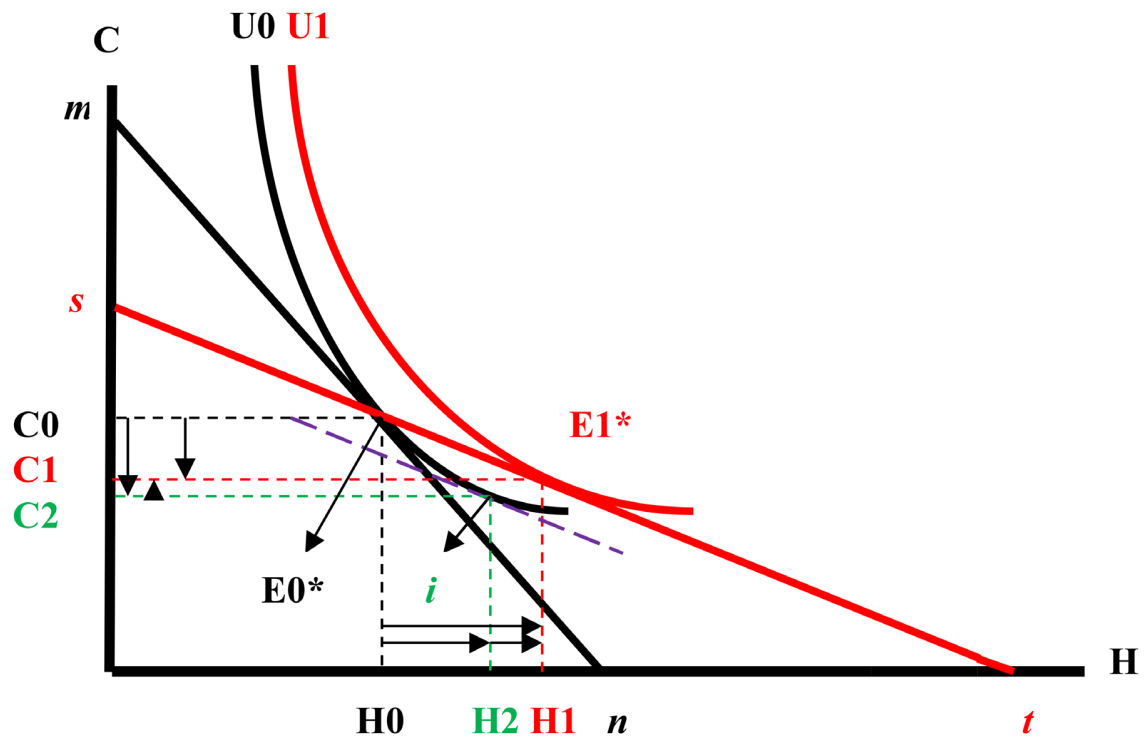

Source: The author creates the figure.

Figure 1. The parent's indifference curves. 
substitution effect. On the other hand, since the relative opportunity cost of holding money for consuming between these two goods drops (i.e., $\frac{P_{H}}{P_{C}} \downarrow$ ), the parent's real income is actually enhanced. Because these two goods (children's education and parents' entertainments) are normal goods, when real income increases, the parent will invest more for children's education (from $\mathrm{H} 2$ to $\mathrm{H} 1$ ) and engage in more entertainments (from $\mathrm{C} 2$ to $\mathrm{C} 1$ ) - that is referred to as an income effect.

As a consequence, due to both substitution and income effects, when the parent raises his/her valuation on the importance of children's education relative to the parent's entertainments (i.e., when $\delta_{H C}$ increases), the parent will increase his/her investment in children's education (from $\mathrm{H} 0$ to $\mathrm{H} 1$ ) and reduce his/her consumption of entertainments (from $\mathrm{C} 0$ to $\mathrm{C} 1$ ). Hence, the parent's utility (well-being) eventually will improve (from U0 to U1). Simply speaking, parents who believe that investing in their children's education is relatively more important than engaging in their own entertainments are more likely to be satisfied with this choice, which will advance their well-being.

\section{Conclusion}

The theory of consumer choice was adopted in this study to model the relationship between parents valuing the importance of children's education relative to parents' entertainment and their investment behavior in their children's education. The theoretical evidence suggests that the relationship is positive, implying that when parents increase their valuation on the importance of their children's education relative to their own entertainments, they signal that they are more willing to invest in their children's education.

In addition, we further investigated the effect of parents valuing the importance of children's education relative to parents' entertainment on parents' utility (i.e., well-being). The effect is uncertain-it may be positive or negative. If the ratio of the percentage decrease in the opportunity cost of holding money to invest in children's education and the percentage increase in the opportunity cost of holding money to expend on entertainments is higher than the ratio of the share of parents' entertainments and the share of children's education, then the effect will be positive. However, with graphical proof, we found a certain and clear positive effect. That is, parents' utility (well-being) actually improves when parents increase their valuation on the importance of children's education relative to parents' entertainment. For that reason, we suggest that parents may invest more time and money in children's education since children's education is worth investing and it is a valuable investment.

The limitation of this research is that we assume that every parent's utility function exhibits the Cobb-Douglas form, which is simple and easy to solve the problem. However, in reality, it is possible that some parents' utility functions may display a different form other than the Cobb-Douglas form, such as the CES 
form. If this is the case, the results could be different. We leave this issue for future research.

Finally, this study's main contribution is in offering an economic theoretical model that can be useful in constructing empirical models for further investigation of this issue.

\section{Conflicts of Interest}

The author declares no conflicts of interest regarding the publication of this paper.

\section{References}

Armer, M., \& Liu, C. (1993). Education's Effect on Economic Growth in Taiwan. Comparative Education Review, 37, 304-321. https://doi.org/10.1086/447192

Dan, B. K. (2020). Mother Labor Participation and Family Education Investment Behavior: An Empirical Study Based on the 2010 Chinese Family Panel Studies (CFPS). Modern Economy, 11, 62-78. https://doi.org/10.4236/me.2020.111007

Fan, J. X., \& Lewis, J. K. (1999). Budget Allocation Patterns of African Americans. Journal of Consumer Affairs, 33, 134-164. https://doi.org/10.1111/j.1745-6606.1999.tb00764.x

Grant, C. (2017). The Contribution of Education to Economic Growth. K4D Helpdesk Report. Institute of Development Studies.

Hao, L. X., \& Yeung, W.-J. (2015). Parental Spending on School-Age Children: Structural Stratification and Parental Expectation. Demography, 52, 835-860. https://doi.org/10.1007/s13524-015-0386-1

Lin, T. C. (2003a). Education, Technical Progress, and Economic Growth: The Case of Taiwan. Economics of Education Review, 22, 213-220. https://doi.org/10.1016/S0272-7757(02)00030-4

Lin, T.-C. (2003b). The Parental Choice of Education: Income Inequality and Endogenous Growth. Journal of Economics, 29, 37-66.

Lin, T.-C. (2004). The Role of Higher Education in Economic Development: An Empirical Study of Taiwan Case. Journal of Asian Economics, 15, 355-371. https://doi.org/10.1016/j.asieco.2004.02.006

Lin, T., \& Lv, H. (2017). The Effects of Family Income on Children's Education: An Empirical Analysis of CHNS Data. Research on Modern Higher Education, 4, 49-54.

Mercan, M., \& Sezer, S. (2014). The Effect of Education Expenditure on Economic Growth: The Case of Turkey. Procedia-Social and Behavioral Sciences, 109, 925-930. https://doi.org/10.1016/j.sbspro.2013.12.565

Meyer, B. D., \& Sullivan, J. X. (2008). Changes in the Consumption, Income, and Well-Being of Single Mother Headed Families. American Economic Review, 98, 2221-2241. https://doi.org/10.1257/aer.98.5.2221

Omori, M. (2010). Household Expenditures on Children, 2007-08. Monthly Labor Review, September, 3-16.

Tallman, E., \& Wang, P. (1994). Human Capital and Endogenous Growth: Evidence from Taiwan. Journal of Monetary Economics, 34, 101-124. https://doi.org/10.1016/0304-3932(94)01152-4 